\title{
Desarrollo rural, movilización política e institucionalización: la experiencia asociativa de los pequeños productores familiares del departamento Vera en el norte santafesino
}

\author{
Urcola, Marcos Andrés \\ Desarrollo rural, movilización política e institucionalización: la experiencia asociativa de los pequeños \\ productores familiares del departamento Vera en el norte santafesino \\ Mundo Agrario, vol. 21, núm. 46, 2020 \\ Universidad Nacional de La Plata, Argentina \\ Disponible en: http://www.redalyc.org/articulo.oa?id=84562590010 \\ DOI: https://doi.org/10.24215/15155994e136
}

Esta obra está bajo una Licencia Creative Commons Atribución-NoComercial-Compartirlgual 4.0 Internacional. 


\section{Desarrollo rural, movilización política e institucionalización: la experiencia asociativa de los pequeños productores familiares del departamento Vera en el norte santafesino}

Rural development, political mobilization and institutionalization: the associative experience of the small family producers of the department Vera in the north of Santa Fe

Marcos Andrés Urcola

DOI: https://doi.org/10.24215/15155994e136

Consejo Nacional de Investigaciones Cientificas y Técnicas

Redalyc: http://www.redalyc.org/articulo.oa?id=84562590010

(CONICET), Facultad de Ciencia Politica y Relaciones

Internacionales, Universidad Nacional de Rosario (UNR),

Argentina

murcola@hotmail.com

Recepción: 27 Septiembre 2019

Aprobación: 04 Diciembre 2019

\section{Resumen:}

El artículo se propone explorar el universo de nuevas formas de organización y acción colectiva que surgen incipientemente en el contexto de la década de 1990 y que tienden a consolidarse a partir del nuevo milenio en torno a la figura de la agricultura familiar. Con un diseño metodológico de caso y enmarcado teóricamente en la perspectiva de los estudios de la acción colectiva (movilización de recursos y nuevos movimientos sociales), se presentan los resultados de un estudio exploratorio sobre la experiencia asociativa de la Unión de Familias Organizadas de Pequeños Productores de la Cuña Boscosa y los Bajos Submeridionales (UOCB) en el norte de la provincia de Santa Fe (Argentina).

Palabras clave: Acción colectiva, Asociativismo, Agricultura familiar, Santa Fe.

\section{Abstract:}

The article seeks to explore the universe of new forms of organization and collective action that are emerging in the context of the 1990 s and that tend to consolidate from the new millennium around the figure of family farm. With a case methodological design and theoretically framed in the perspective of collective action studies (mobilization of resources and new social movements), we present the results of an exploratory study on the associative experience of the Unión de Familias Organizadas de la Cuña Boscosa $y$ los Bajos Submeridionales (UOCB) in the north of the Province of Santa Fe (Argentina).

KeYWORDS: Collective action, Associativism, Family farm, Santa Fe.

\section{INTRODUCCIÓN}

El sector agropecuario argentino se expresa en la actualidad en una densa red asociativa construida a partir de diversas formas organizativas y tramas de articulación público-privadas, en las que participan productores agropecuarios y población rural de diferentes condiciones y disponibilidad de recursos económicos y productivos.

Esta red asociativa se ha ido construyendo desde los inicios de la agricultura en la Argentina, como lo reflejan la aparición de las primeras organizaciones gremiales y económicas (cooperativas) hacia fines del siglo XIX (Lattuada, 2006). No obstante, la retracción del Estado en la década de 1990, los cambios estructurales en la economía y una serie de problemas comunes a las asociaciones reivindicativas agrarias tradicionales (Sociedad Rural Argentina, Federación Agraria Argentina, Confederación Intercooperativa Agropecuaria y Confederaciones Rurales Argentinas) ${ }^{1}$ contribuyeron a una intensificación del pluralismo asociativo en el agro, con el surgimiento de cientos de nuevas asociaciones o proyectos asociativos, en algunos casos autogenerados por las condiciones del nuevo contexto económico, y en otros, promovidos activamente por 
los programas de desarrollo rural focalizados, tanto públicos como privados, que incorporaron la estrategia asociativa como base de su intervención en favor de los sectores de la agricultura familiar (Lattuada, Nogueira y Urcola, 2015; Cerdá y Salomón, 2017).

En Argentina, la agricultura familiar no había sido históricamente una cuestión relevante en la agenda sectorial. Sin embargo, en la primera década del siglo XXI, su problemática fue creciendo en importancia en la región del Mercado Común del Sur \#MERCOSUR\# y en el ámbito nacional a partir de una estrategia gubernamental explícita en la reorientación de los programas de desarrollo rural con el objeto de fortalecer la organización y representación de intereses de estos sectores rurales postergados (Nogueira y Urcola, 2013).

Las experiencias observadas (Lattuada et al., 2015) sugieren que, a pesar de la progresiva disminución de la población rural y del número de establecimientos de pequeños y medianos productores agropecuarios, en la Argentina se ha incrementado el número de asociaciones de todo tipo con una amplia dispersión territorial y fuerte anclaje local que fueron progresivamente organizándose y aun integrándose en redes de organizaciones como el Foro Nacional de la Agricultura Familiar (FoNAF).

Sobre ese universo de nuevas formas de organización y acción colectiva que surgen incipientemente en el contexto de la década de 1990 y que tienden a consolidarse a partir del nuevo milenio en torno a la figura de la agricultura familiar nos hemos concentrado en el marco del estudio en curso.

Estos procesos se encuentran operando en el ámbito rural y plantean numerosos interrogantes sobre su dimensión, característica y potencialidad: ¿Cuál es la fuente de aglutinación de los actores que confluyen en estas organizaciones? ¿Cómo canalizan sus demandas y a través de qué prácticas y lógicas políticas lo hacen? ¿Qué lugar ocupa la agricultura familiar en los discursos y programas reivindicativos de estas organizaciones en función de la articulación de los diversos intereses de su base social y del diseño de estrategias de acción colectiva que les sean propias?

A partir de estos interrogantes, hemos seleccionado una experiencia asociativa que nos permitió una aproximación empírica al estudio de las formas asociativas de la agricultura familiar del último tiempo. En términos generales, nos referimos a la noción de experiencia asociativa para hacer hincapié en el carácter procesual y complejo del caso analizado, intentando recuperar el contexto de su conformación y desarrollo como respuesta a una realidad particular que la ha modelado (Cerdá y Salomón, 2017), y a la acción colectiva para referirnos a los procesos de movilización social que motivaron a los sujetos a cooperar entre sí (Lattuada, 2006).

En este artículo presentamos el análisis del proceso de constitución y desarrollo de la Unión de Familias Organizadas de Pequeños Productores de la Cuña Boscosa y los Bajos Submeridionales (UOCB) en el norte de la provincia de Santa Fe (Argentina). La reconstrucción y análisis del caso propuesto ofrece un recorrido que va desde la movilización social de los actores dispersos que comienzan a agruparse en el marco de acciones para el desarrollo rural de una ONG (FUNDAPAZ) en la década de 1990 hasta la institucionalización de sus acciones en el marco de una asociación civil con personería jurídica (la UOCB) en 2010 para vincularse de diferentes maneras con otros actores políticos (locales e internacionales) y ocupar los espacios de interlocución con el Estado en sus diferentes niveles.

Con un diseño metodológico de caso (Yin y Helad, 1975) y enmarcado teóricamente en la perspectiva de la acción colectiva, se presentan los resultados de un estudio exploratorio sobre la experiencia asociativa de los pequeños productores familiares del departamento Vera en el norte de la provincia de Santa Fe, teniendo en cuenta sus particularidades como organización relativamente reciente y poco documentada en la provincia y el interés que dicho caso reviste para dar respuesta a los interrogantes planteados anteriormente.

Durante su estudio, se tuvieron en cuenta aspectos vinculados a los factores que han propiciado la articulación de intereses entre los asociados de esta organización, el tipo de asociación y estructura de representación resultante, los discursos a partir de los cuales se identificaron y diferenciaron de otros actores del agro, y las esferas donde desarrollaron mayoritariamente sus estrategias de acción (en el ámbito público del Estado o el privado de la sociedad civil). ${ }^{2}$ Esto nos llevó progresivamente a tomar elementos conceptuales de 
la perspectiva de la movilización de recursos (Tilly, 1990; McAdam, McCarthy y Zald, 1999; Tarrow, 2004) y de los nuevos movimientos sociales (Touraine, 1985; Offe, 1992; Melucci, 1999) como claves analíticas y fuentes explicativas de la experiencia asociativa bajo estudio.

Teniendo en cuenta estos aspectos, el artículo se estructura con un apartado en el que exponemos los aspectos centrales de la discusión entre estas dos corrientes teóricas. En otro apartado realizamos una breve reseña del proceso de movilización social y política de la UOCB que oficia de caso empírico de estudio. A continuación, ordenamos expositivamente el artículo a través del uso operativo de algunas categorías propias de estas teorías que nos han permitido desagregar la experiencia asociativa bajo análisis en función de las estructuras de oportunidades políticas; las estructuras movilizadoras y estrategias de acción; y las producciones discursivas y marcos interpretativos para la acción. Con fines descriptivos e interpretativos, dichas categorías nos han posibilitado un pertinente diálogo entre el proceso empírico estudiado y las respuestas a los interrogantes teóricos planteados.

\section{Aspectos teóricos SOBRE MOVILIZACión DE RECURSOS Y NUEVOS MOVIMIENTOS SOCIALES}

Las teorías de la movilización de recursos y de los nuevos movimientos sociales se ofrecen hoy en día como los dos enfoques privilegiados por las ciencias sociales para interpretar la acción colectiva.

La teoría de la movilización de recursos pone en el centro de la discusión la racionalidad y los incentivos como determinantes de la participación en la movilización, haciendo hincapié en las acciones institucionalizadas de los actores. En esta perspectiva, las actividades de los movimientos se organizan sobre la base de intereses compartidos y sobre la posibilidad de contar con los recursos necesarios que remiten a la capacidad de influir sobre los medios institucionales y de toma de decisión (Natalucci, Pérez, Shuster y Gattoni, 2013). Parte del supuesto de que en la sociedad existen recursos (poder, prestigio, dinero, etc.) que se encuentran desigualmente distribuidos y que las injusticias sociales no son una excepción del orden social, sino una regularidad de su modo de funcionamiento, que motoriza a los diferentes grupos sociales hacia la acción contenciosa (Iglesias, 2008). De este modo, promueve una concepción de la política como la posibilidad de acceso a instituciones existentes, otorgando centralidad al accionar del Estado o del sistema político. El grado de apertura del sistema político y las iniciativas estatales son las que determinan el momento y el modo de la acción colectiva, entendidos por este enfoque como "oportunidades políticas" (Tarrow, 1999).

En cambio, la teoría de los nuevos movimientos sociales pone el acento en los aspectos culturales y simbólicos que hacen a la integración de los grupos sociales, intentando superar el reduccionismo de lo político a lo institucional y lo organizativo. En esta perspectiva, los conflictos no se desencadenan en torno a problemas de distribución, sino en torno a la defensa o promoción de (nuevas o alternativas) formas de vida. Lo político se afirma sobre los valores y el conjunto de significaciones sociales que los protagonistas les atribuyen a sus acciones comunes. La organización política de la sociedad civil se explica por la interacción de los grupos sociales que la integran y las iniciativas estatales son entendidas como contexto o trasfondo necesario para la explicación. En este sentido, las trayectorias identitarias de los grupos sociales constituyen un punto de partida de sus reflexiones teóricas. Para esta perspectiva, la articulación contingente entre distintos actores que ocupan diferentes lugares en el tejido social implica la consolidación de una identidad, en tanto momento político que permite transformar identidades sociales en identidades políticas (Iglesias, 2008; Natalucci, 2011; Seoane, Taddei y Algranati, 2011).

Tal como sostiene Iglesias (2015), entre considerar al Estado como eje explicativo o como mero contexto, se abre un campo a explorar que es el de la mutua incidencia entre la implementación de iniciativas estatales y el accionar de los movimientos o grupos sociales en el marco de acciones instituyentes y destituyentes. Para la teoría de la movilización de recursos, si los movimientos no se institucionalizan fracasan, dado que no logran 
incorporar sus demandas a las instituciones políticas. Mientras que, para la teoría de los nuevos movimientos sociales, estos fracasan si se institucionalizan porque quedan capturados por el sistema de relaciones que pretenden impugnar. De este modo, para la primera el Estado no representa un problema, sino más bien el eje central de su propósito estratégico. En cambio, para la segunda el Estado es fuente de cooptación, burocratización o cosificación que le quita vitalidad al movimiento.

A pesar de estas diferencias y puntos centrales de discusión, Natalucci et al. (2013) sostienen que ambos enfoques coinciden en la concepción general del proceso de institucionalización. Los movimientos emergen de una falencia del sistema institucional para reintroducirse como intereses en un sistema representativo o como un cambio parcial en el sistema. A su vez, ambos enfoques comparten la idea de que la política se cristaliza en instituciones y, centralmente, en el Estado, en tanto sistema político de representación de intereses. Esto ha conllevado a plantear un encuadre analítico que divide taxativamente Estado y sociedad civil y lo político de lo social. En pos de superar esta falsa dicotomía, coincidimos con estos autores cuando afirman que la institucionalización no es un punto de llegada o de clausura sino un aspecto fundamental de los procesos políticos conflictivos que impulsan la acción colectiva.

Teniendo en cuenta estos aspectos, consideramos que los actores sociales y sus procesos de movilización colectiva no son puros y siempre combinan acciones tendientes a la institucionalización con otras de corte defensivas o destituyentes. Las respuestas de las organizaciones o movimientos sociales a participar o a oponerse a un gobierno o a iniciativas estatales de diverso tipo no se explican a partir de cualidades esenciales propias de su accionar ni a sus lógicas de acción política, sino “a partir de la sistemática y mutua incidencia entre cultura política existentes en una sociedad y el impacto de las iniciativas estatales en el modo que asume la acción contenciosa" (Iglesias, 2015, p. 151).

Por ello, nos parece relevante destacar que, a pesar de las divergencias y enfrentamientos históricos entre estos dos enfoques teóricos, hay que advertir que en los procesos organizativos y de movilización social concretos siempre se hallan presentes ambas lógicas de la acción colectiva, aunque no siempre con la misma intensidad (Svampa, 2008; Iglesias, 2008). La hibridez del caso que presentamos a continuación nos da argumentos para sostener estas afirmaciones.

\section{BREVE CARACTERIZACIÓN DE LA UOCB Y SU PROCESO HISTÓRICO DE CONFORMACIÓN}

La Unión de Familias Organizadas de Pequeños Productores de la Cuña Boscosa y los Bajos Submeridionales (UOCB) es una organización de más de 600 asociados del departamento Vera en el norte de la provincia de Santa Fe, que fue creada como asociación civil sin fines de lucro en octubre de 2010.

Su zona de influencia abarca dos áreas del norte provincial chaqueño: la Cuña Boscosa, un mosaico de montes con quebrachos, algarrobos, arbustos, esteros y cañadas, y los Bajos Submeridionales, un humedal de más de tres millones de hectáreas, con extensos pastizales y ambientes acuáticos casi sin caminos, y con un limitado desarrollo económico.

En esta zona, su accionar está dirigido a las familias “criollas" de pequeños productores y pobladores que viven en comunidades rurales pertenecientes a las localidades de Vera, La Gallareta, Fortín Olmos, Toba, Garabato, Tartagal, Intiyaco, Los Tábanos, Golondrinas, Los Amores, Fortín Charrúas y Santa Lucía. ${ }^{3}$

A pesar de que su formalización es de reciente data, el proceso de construcción organizacional y movilización política de la UOCB se remonta a más de 25 años de trabajo en grupos de familias de diferentes parajes del departamento Vera. Más específicamente, sitúa su origen en los grupos de desarrollo rural promovidos por la Fundación para el Desarrollo en Justicia y Paz (FUNDAPAZ) desde la década de 1980. ${ }^{4}$ Estos grupos se conformaron primero alrededor de temáticas o problemáticas comunes (acceso al agua, regulación de tierras, producción animal, etc.) y luego en función de la pertenencia territorial a un paraje o localidad rural del departamento Vera, de donde han salido los "referentes de paraje" que hoy en día componen la Comisión Directiva de la UOCB. 
Cada uno de estos grupos y parajes tuvo su historia y dinámica propia, pero con el correr del tiempo lograron articular sus acciones y experiencias en la construcción de una historia común. En este sentido, de particular relevancia resultaron dos hechos:

1- Por un lado, la gestión de recursos realizada por FUNDAPAZ, a través de organismos internacionales, para la construcción de salones comunitarios y para proyectos productivos. Estos recursos permitieron la organización de la vida comunitaria en los parajes que, luego, derivarían en asociaciones vecinales y en la generación (en 1991) de un Fondo Rotatorio de crédito para autofinanciarse en aspectos productivos y habitacionales (mejoras de las viviendas). El proceso de organización de los grupos vecinales en torno a los problemas de los parajes (fundamentalmente de acceso al agua potable) y la organización de una Comisión para administrar el otorgamiento de los créditos de todos los grupos y el seguimiento de sus devoluciones resultaron fundamentales para romper la fragmentación de intereses entre los pobladores y los grupos de estos parajes rurales. La UOCB no existía como organización, pero quienes participaban de los grupos de desarrollo rural promovidos por FUNDAPAZ ya empezaban a pensarse como partes de un proyecto común.

2- Por otro lado, y tal vez el de mayor relevancia en términos de articulación de acciones e intereses (según los testimonios de sus diversos actores), fue un conflicto de tierras que comienza en 1992 y que comprendía a varias familias de la zona de la cuña boscosa. El intento del gobierno provincial de poner en venta las tierras fiscales informalmente ocupadas por ellas desde hacía varias décadas los llevó a organizarse en defensa de sus tierras, para lo cual recurrieron a FUNDAPAZ. Esta ofició de mediadora entre las familias afectadas y las autoridades provinciales, y las relacionó, a su vez, con la Fundación de Servicios Jurídicos Solidarios de Reconquista (vinculada al obispado), que los acompañó en todo el proceso de reclamo y posterior proceso de regularización y titulación de tierras mediante la sanción de la ley 12.091 (del año 2002). Esto dio lugar a una comisión específica que aglutinó a referentes de diferentes parajes afectados con los cuales se comenzó a trabajar el tema de las tierras donde vivían algunas familias específicas, pero también el de los denominados "lotes pueblo", ${ }^{5}$ donde estaban asentadas varias familias juntas sin título de propiedad. Este proceso de lucha implicó no sólo la unión de las familias afectadas y sus vecinos solidarios, sino que también los obligó a salir de los parajes rurales para hacerse escuchar frente a diferentes actores del ámbito gubernamental local y provincial, estableciendo procesos de diálogo y confrontación con otros actores de la sociedad civil con intereses en la misma zona (por ejemplo, productores nucleados en la Sociedad Rural Argentina, comunidades aborígenes nucleadas en OCASTAFE y la Asociación Amigos del Aborigen, entre otros).

En este sentido, podemos afirmar que la UOCB fue germinando como organización en la década de 1990 a partir del proceso de lucha por la tierra y de actividades productivas y comunitarias vinculadas con la administración de fondos para créditos e infraestructura comunitaria gestionados y promovidos por FUNDAPAZ en el marco de sus estrategias de desarrollo rural.

El acompañamiento en el proceso de consolidación organizacional realizado por FUNDAPAZ tuvo su "broche de oro" en el año 2010 con la conformación de la UOCB como Asociación Civil y en el año 2016 con la inauguración de un salón multiuso que oficia de sede social en la localidad de Vera. Así, entre los años 2000 y 2010 , podemos situar el proceso de institucionalización y consolidación de las acciones emprendidas durante la década anterior.

\section{ESTRUCTURA DE OPORTUNIDADES POLÍTICAS}

Para Tarrow (2004), la acción colectiva prolifera cuando la gente tiene acceso a los recursos necesarios para escapar a su pasividad habitual y encuentra oportunidad de usarlos. En esta perspectiva, se pone especial énfasis en los recursos exteriores al grupo, dando centralidad al grado de apertura o cierre del sistema político y a las iniciativas estatales. Tarrow ha denominado "estatalismo dinámico" a esta mutua influencia entre acción colectiva y Estado. 
De este modo, el concepto de “oportunidades políticas" permite explicar cómo categorías sociales (trabajadores, campesinos, pobladores rurales, etc.) se transforman en identidades políticas, privilegiando el análisis de la acción político-contenciosa como un salto contingente que tiende puentes entre las condiciones sociales preexistentes y un nuevo escenario en el que los sujetos se involucran de un modo en el que no lo estaban con anterioridad (Schuster, 2005).

Las dimensiones básicas de este concepto son la apertura del acceso a la participación de nuevos actores; las pruebas de nuevas alianzas políticas en el seno del gobierno; la aparición de aliados influyentes; la aparición de divisiones entre los dirigentes y una disminución en la capacidad o la voluntad del Estado de permitir la disidencia (Tarrow, 2004, p. 116). A su vez, estas dimensiones pueden contemplarse en función de tres tipos de contextos: local, nacional e internacional (Martínez Espinoza, 2006).

En el caso analizado, estos tres contextos son centrales. Las acciones locales de promoción del desarrollo rural de una ONG, primero, y el auge y jerarquización institucional de las temáticas del desarrollo rural y la agricultura familiar a nivel nacional e internacional, después, oficiaron de base para su movilización. Mientras que las disputas político-partidarias en el ámbito provincial y, a su vez, entre los gobiernos provincial y nacional en diferentes momentos del proceso de conformación de la UOCB oficiaron de incentivos para la acción.

\subsection{Promoción del desarrollo rural e institucionalización de la agricultura familiar}

Desde los 80 y principios de los 90, FUNDAPAZ desarrollaba una estrategia interventiva en línea con los denominados Programas de Apoyos Integrados Basados en la Demanda que, a grandes rasgos, consistían en brindar una serie de apoyos (técnicos, financieros, organizacionales, etc.) en función de las demandas y problemáticas específicas de cada población.

Estos procesos de promoción y asesoramiento llevados adelante por FUNDAPAZ fueron acompañados, a su vez, por acciones de formación de dirigentes que permitieron los posteriores procesos de integración y autonomía de esta organización. A principios del nuevo milenio, los técnicos de FUNDAPAZ cambian su estrategia de intervención y dejan de realizar las tareas de promoción y asistencia a los grupos en el territorio, lo que da lugar a que dichas tareas sean realizadas por referentes de los parajes rurales formados a través de los años.

A esta trayectoria organizacional de base hay que sumar el contexto de discusión e institucionalidad de la temática de la agricultura familiar en el ámbito de las políticas públicas de desarrollo rural promovido a nivel nacional y regional, fundamentalmente a partir del 2000 (Nogueira y Urcola, 2013). Dichas políticas han cumplido un rol vertebrador que ofició de marco para la promoción de acciones de cooperación, confrontación o ambas a la vez entre los actores vinculados a la pequeña producción campesina, indígena y/ o familiar durante el período analizado.

El peso histórico de la Federación Agraria Argentina (FAA) como organización nacional representativa de los pequeños productores con origen y base social en el sur de la provincia y la experiencia trunca de las Ligas Agrarias en el norte en la década de 1970 (Archetti, 1988) hicieron que la pequeña producción familiar de base campesina no estuviera claramente representada en Santa Fe (como sí ocurrió en las provincias de Santiago del Estero o de Misiones) y hasta invisibilizada por el peso simbólico del sujeto agrario pampeano.

Buena parte de los grupos o asociaciones de pequeños productores campesinos que hoy se aglutinan como organizaciones de la agricultura familiar en Santa Fe y el país han sido movilizados inicialmente, en la década de 1990, a partir de diferentes programas de desarrollo rural que han privilegiado los territorios extrapampeanos del norte del país para sus intervenciones. Posteriormente, estos grupos y asociaciones fueron fortalecidos en su capacidad de organización con la creación de la Reunión Especializada de la Agricultura Familiar (REAF) del MERCOSUR (en 2004), el Foro Nacional de la Agricultura Familiar (FoNAF, en 2006) y la constitución de las respectivas mesas provinciales de este Foro, con el apoyo de la Secretaría de 
Desarrollo Rural y Agricultura Familiar de la Nación en sus diferentes etapas (desde 2008 hasta 2016), a través de la coordinación provincial de la Subsecretaría de Agricultura Familiar (SAF) (véase Urcola, 2018).

Lo que queremos indicar con esta breve y esquemática referencia es la realidad divergente en la construcción histórica del sujeto agrario y sus formas organizativas en el territorio santafesino, que comienza a reconfigurarse en el marco de la discusión nacional en torno al desarrollo rural, primero, y la agricultura familiar, después.

\subsection{Disputas político-partidarias y entre estructuras estatales de gestión}

El proceso de movilización social y política que da como resultado la conformación de la UOCB se da en un contexto de alta conflictividad y alternancia entre partidos políticos que se disputan la gobernación de la provincia y, a su vez, por el vínculo inestable de las estructuras estatales de gestión provinciales con las nacionales.

Desde la vuelta a la democracia (1983) hasta el 2007, la provincia de Santa Fe ha sido gobernada por diferentes personalidades y facciones partidarias del Partido Justicialista (PJ o peronismo). Mientras que, entre 2007 y 2019, ha sido gobernada por el Frente Progresista, una alianza política de base provincial entre el Partido Socialista (PS) y la Unión Cívica Radical (UCR).

El cambio de signo político del gobierno provincial en 2007 es de especial relevancia, en términos de oportunidades políticas, para el proceso de conquistas reivindicativas y consolidación institucional de la UOCB.

Ya hemos mencionado que el conflicto por la defensa de sus tierras fue uno de los aspectos centrales que motorizó los procesos de movilización política y organización colectiva de estos pequeños productores y habitantes de la cuña boscosa, al mismo tiempo que consolidó su vínculo con FUNDAPAZ como institución mediadora y referente para la defensa de sus derechos. Si bien este proceso de lucha arranca en 1992 y obtiene su primer logro en 2002 con la sanción de la ley 12.091 de regularización y titulación de tierras, recién en 2009 se logra llevar adelante la efectiva adjudicación de las tierras a partir del diálogo con las autoridades del nuevo partido gobernante. ${ }^{6}$

A través de un referente zonal vinculado al obispado de Reconquista, que ya los conocía y que fue diputado provincial y nacional del Frente Progresista, logran establecer un puente de diálogo con la instancia de gobierno que antes no tenían (audiencias con funcionarios y Ministro de la Producción, y hasta el propio Gobernador). Esta articulación y la efectiva entrega de los títulos significaron "un antes y un después" en el proceso de consolidación organizacional y posterior institucionalización de la UOCB, puesto que materializaron exitosamente uno de sus reclamos históricos y los afianzaron como interlocutores frente a las distintas instancias del gobierno provincial que, al ser de un nuevo signo político, intentaba distanciarse de la anterior gestión y, a la vez, marcar sus diferencias respecto del gobierno nacional con el cual comenzaban a tener enfrentamientos.

Con el nuevo gobierno socialista (...) nos fue más fácil llegar tanto al Ministerio de la Producción como a los gobernantes. Desde el gobernador Binner que apareció en la localidad de Charrúa para entregar los primeros títulos de tierra gestionados por nuestra organización y ahí cambió la historia de todo (...). Anteriormente no nos recibían, pero la UOCB tampoco estaba igual de constituida que ahora. Con la organización que vamos teniendo hoy, cualquier gobierno nos recibe en las mismas condiciones porque estamos con una base y una fortaleza... Y al ver esto, los gobernantes decían: 'Ah, acá está la gente de la $\mathrm{UOCB}^{\prime}$, y empezaron a nombrarnos por nuestro trabajo y trayectoria (Tesorero de la UOCB, Entrevista 2/6/16). ${ }^{7}$

En términos de oportunidades políticas hay que remarcar también que la primera tanda de entregas de títulos realizada por el nuevo gobernador cobra impulso durante el año 2008 en el marco del enfrentamiento que tuvo el gobierno nacional con las cuatro organizaciones corporativas tradicionales del sector agropecuario del país (SRA, FAA, CRA y CONINAGRO) por la propuesta de aumento de las retenciones sobre granos 
y carne vacuna, contando a su vez con el apoyo de sectores urbanos medios y altos y de partidos políticos opositores (véase Muzlera, Poggi y Carreras Doallo, 2011). Este conflicto tuvo un gran impacto en la provincia de Santa Fe, donde se sucedieron múltiples cortes de ruta y concentraciones urbanas (como en la ciudad de Rosario). Aunque los pequeños productores del norte provincial (chaqueño) vinculados a la UOCB no se encontraban interpelados ni comprendidos por las demandas concretas que se motorizaban en aquel conflicto de raigambre pampeana, la necesidad del gobierno provincial de distanciarse del gobierno nacional operó como telón de fondo que dio viabilidad política a las acciones insinuadas a partir del cambio de gestión. $^{8}$

A su vez, entre 2003 y 2015 el gobierno nacional estuvo conducido por una coalición política que tuvo como partido mayoritario al Justicialismo (o peronismo), denominada Frente para la Victoria (o kirchnerismo). La relación entre este gobierno nacional y el provincial atravesó diferentes momentos, pero el período que va de 2011 a 2015 se destaca especialmente por el fuerte distanciamiento y confrontación política entre ambos.

En dicho contexto, las divergencias en torno a las acciones para el desarrollo de los territorios rurales entre los técnicos de la Subsecretaría de Agricultura Familiar (SAF) con los de FUNDAPAZ, y la decepción de los referentes de la UOCB participantes de las mesas provinciales del Foro Nacional de la Agricultura Familiar (FoNAF) por el acceso a y la distribución de fondos nacionales, contribuyeron a la conformación de una identidad conflictiva y autónoma de esta organización respecto de los lineamientos del gobierno nacional y más próxima al gobierno provincial en función de las alianzas construidas con algunos de sus dirigentes.

Nosotros participamos de mesas departamentales, mesas provinciales y teníamos referentes regionales para que participen en la nación, pero nunca bajaron fondos de la nación para la provincia. La última vez que bajaron fondos fueron a Catamarca y Buenos Aires. Y la plata que había se gastaba en la estructura técnica para pagar sueldos (Presidente de la UOCB, Entrevista 2/6/16).

(...) El PSA, que luego se transformó en la SAF, es una cosa totalmente distinta y con ellos hemos tenido miles de quilombos, miles de peleas y últimamente ni articulábamos y era imposible la relación por varios motivos. El principal que engloba a todos los otros (...) en la mayoría de los casos no reconocieron nunca las organizaciones campesinas con las que nosotros estábamos trabajando (...). Ellos iban al territorio, al mismo paraje donde sabían que estaba la UOCB y que tenía sus referentes, y hablaban con esa gente para armar un proyecto de agua (...), y cuando les decían que ya tenían grupo, les decían: "No importa, esto es otra cosa, vos armá un proyecto con un grupo de seis personas con un nombre y laburamos en esto". Es decir, la ejecución de recursos les hizo ir en contra de lo que ellos decían que eran sus principales objetivos de fortalecimiento de las organizaciones. Llegaban al territorio, no te reconocían como organización y en los últimos tiempos era peor porque ya se dedicaban directamente a hacer política partidaria (...). Le critico mucho eso al PSA y la SAF, que el fortalecimiento de las organizaciones no fue tal y estuvo viciado por la ejecución de recursos. Sí me parece muy importante haber tenido durante tantos años un programa para los pequeños productores que antes no había, un programa que reconoció la presencia de los pequeños productores y que los apoyó (Director de Programas Provinciales de FUNDAPAZ, Entrevista 16/06/16).

Estas divergencias con la gestión nacional de las políticas destinadas al sector de la agricultura familiar favorecieron la articulación programática entre los proyectos de promoción del desarrollo de los territorios rurales que sostenían los cuadros técnicos de FUNDAPAZ con las necesidades, demandas y expectativas de reconocimiento que planteaban los referentes zonales de la incipiente UOCB y, a su vez, reforzaron una trayectoria de estas dos organizaciones ligadas a la articulación de intereses en el marco de los espacios de interlocución con el Estado provincial para el acceso a recursos y reivindicación de derechos.

Finalmente, en diciembre de 2015 asume la conducción del gobierno nacional la coalición política "Cambiemos", integrada principalmente por dirigentes partidarios de Propuesta Republicana (PRO) y referentes políticos de la Unión Cívica Radical (UCR) y la Alianza Republicana (ARI). Este nuevo escenario, lejos de morigerar la confrontación que había entre las esferas de gobierno nacional (kirchnerista) y provincial (socialista), ha tendido a acentuar la conflictividad política en Santa Fe. No sólo porque la gestión de gobierno nacional (PRO-Cambiemos) tuvo aspiraciones de gobernar la misma, sino también porque los integrantes 
de la UCR que integraban el Frente Progresista comenzaron a abandonar el frente provincial para unirse al proyecto de base nacional que intentaba consolidar Cambiemos.

En este sentido, cabe señalar que los cambios políticos, económicos e institucionales por los que transitó el país desde 2016 abrieron un período de redefinición de los intereses y actores que confluyen en el campo asociativo de la agricultura familiar y que aún está en proceso. La opción de la UOCB de canalizar sus demandas a través del Ministerio de la Producción provincial le sirvió para amortiguar parcialmente las consecuencias de este cambio, en el marco de un Gobierno santafesino que aún pretendía diferenciarse del nacional. No obstante, la salida de la "agricultura familiar" de la agenda política del gobierno nacional ha ofrecido un contexto de "oportunidades políticas" cuyas consecuencias aún no están definidas. En este sentido, en los discursos de los referentes de la UOCB (entre 2016 y 2018) dicho contexto de cambios operó como un escenario de incertidumbre y expectativa, en función de las definiciones de política pública que el gobierno nacional insinuaba, pero no ejecutaba ni definía con claridad (como la reglamentación de la Ley 27.118 de Reparación Histórica de la Agricultura Familiar), al mismo tiempo que consolidaba su relación fluida con las autoridades del gobierno provincial.

En síntesis, el contexto de oportunidades políticas que se abre en 2007 con el cambio de signo político del gobierno provincial y el proceso de jerarquización institucional de las temáticas del desarrollo rural y la agricultura familiar llevadas adelante por el gobierno nacional a partir del conflicto agropecuario de 2008 ofrecieron un escenario de estatalidades dinámicas que favorecieron los procesos de organización e institucionalización llevados adelante por los referentes de las localidades y parajes rurales patrocinados por FUNDAPAZ desde la década de 1990 y que en 2010 logran constituirse formalmente en la Asociación Civil UOCB.

\section{EstruCturas MOVILIZADORAS, IDENTIDAD Y ESTRATEgIAS DE ACCIÓN}

La tensión entre la dimensión cultural (identitaria) con la dimensión política (organizacional) que todo proceso de movilización colectiva implica está presente en el debate entre las perspectivas teóricas de la movilización de recursos y los nuevos movimientos sociales.

A pesar del mayor o menor énfasis que cada uno de esos enfoques teóricos realiza sobre estas dimensiones, no parece haber una real oposición entre ellas, ya que ambas dan un lugar central a la interacción entre lo organizacional y lo identitario. Cuestión que resulta evidente y analíticamente pertinente para el caso estudiado.

Tal como señala Iglesias (2008), luego de los planteos fundacionales de Olson (1992) nadie considera que la organización sea previa a la acción colectiva y, en términos generales, se tiende a señalar que aquella constituye un recurso, al igual que la cultura, el dinero, el prestigio y el poder, que es central para la efectivización de la acción colectiva.

Para el caso de las familias de pequeños productores integrados bajo el nombre de la UOCB que estamos analizando, lo organizacional ha tomado gran relevancia actual, en la medida en que ha permitido formalizar muchas de sus acciones para el diálogo político con las esferas gubernamentales y consolidar una estructura funcional y movilizadora de representación territorial del departamento Vera. No obstante, la secuencia histórica de su constitución nos permite observar cómo los procesos organizativos fueron madurando con la necesidad de constituir un "nosotros" que les permitiera aglutinarse y dar visibilidad a sus reclamos y demandas particulares en los diferentes contextos antes reseñados y en el marco de las redes institucionales y gubernamentales que les dieron cobijo e impulso. De este modo, lo organizacional ha operado tanto en su dimensión instrumental (como recurso) como en su dimensión expresiva (identitaria). 


\subsection{Estructuras movilizadoras}

En el proceso de organización de la UOCB, FUNDAPAZ operó como institución que estimuló la participación de los actores comprendidos en el marco de sus acciones para el desarrollo rural y funcionó como red de contención para la articulación de intereses latentes, dándoles visibilidad y generando nuevos sentidos (Melucci, 1999).

La necesidad de hacer visibles sus problemáticas y demandas específicas ha operado como principio para la movilización política (Melucci, 1999), mientras que la inscripción territorial de sus prácticas sociales y productivas ha funcionado como eje identitario y cohesionador para la acción colectiva. Tanto la UOCB como otros casos similares del campo asociativo de la agricultura familiar desde el 2000 a esta parte se han movilizado sobre la base de territorios o localidades organizadas; es decir, sobre la base de una identidad territorial que los ha integrado y dado sentido en su acción (Urcola, 2018).

La estructura organizacional que se formaliza a partir de 2010 refleja la necesidad de consolidar un modelo de representación colectiva y sectorial a nivel departamental que supere la dispersión territorial de los parajes rurales y que, a su vez, mantenga un canal de diálogo constante y democrático entre los dirigentes y las comunidades locales a las que representan.

Hoy en día, la UOCB tiene presencia en 32 parajes rurales del departamento Vera. Su órgano máximo de gobierno es la Asamblea, a partir de la cual se designa una Comisión Directiva (de 16 personas) y una Secretaría Ejecutiva (integrada por cinco personas: presidente, vicepresidente, tesorero, secretario y administrativo) que trabaja con los Referentes Zonales. Cuenta con nueve Comisiones Zonales donde se reúnen mensualmente los Referentes de Paraje para abordar las problemáticas comunes de los asociados de cada zona específica del departamento (agrupadas en función de su proximidad) (véase Figura 1).

Acá es muy difícil juntarse por la distancia. Tenemos $200 \mathrm{~km}$ de Sur a Norte y $180 \mathrm{~km}$ de Este a Oeste (...). Entonces empezamos a agrupar a los grupos que estaban más cerca e hicimos una zona y así se armaron nueve zonas (...). Algunos parajes como el de Tartagal están tan lejos que quedaron solos como un grupo. (...) Así trabajamos por zonales, con una Comisión Zonal integrada por tres o cuatro personas que, a su vez, se juntan tres veces al año y los parajes son los que concentran la información. (...) En cada paraje hay un referente de paraje que es muy importante como lazo con la gente del paraje y la organización (Tesorero de la UOCB, Entrevista 2/6/16).

En términos de representación, cabe destacar que se observa gran participación de mujeres desempeñándose como referentes de paraje y ocupando distintos roles en la composición de la Comisión Directiva. En 2012 la UOCB contaba con 46 referentes de paraje, de los cuales el 63 \% eran mujeres y el 17 \% varones y, para el mismo año, su Comisión Directiva estaba integrada (entre titulares y suplentes) por 9 mujeres y 7 varones. $^{9}$ 


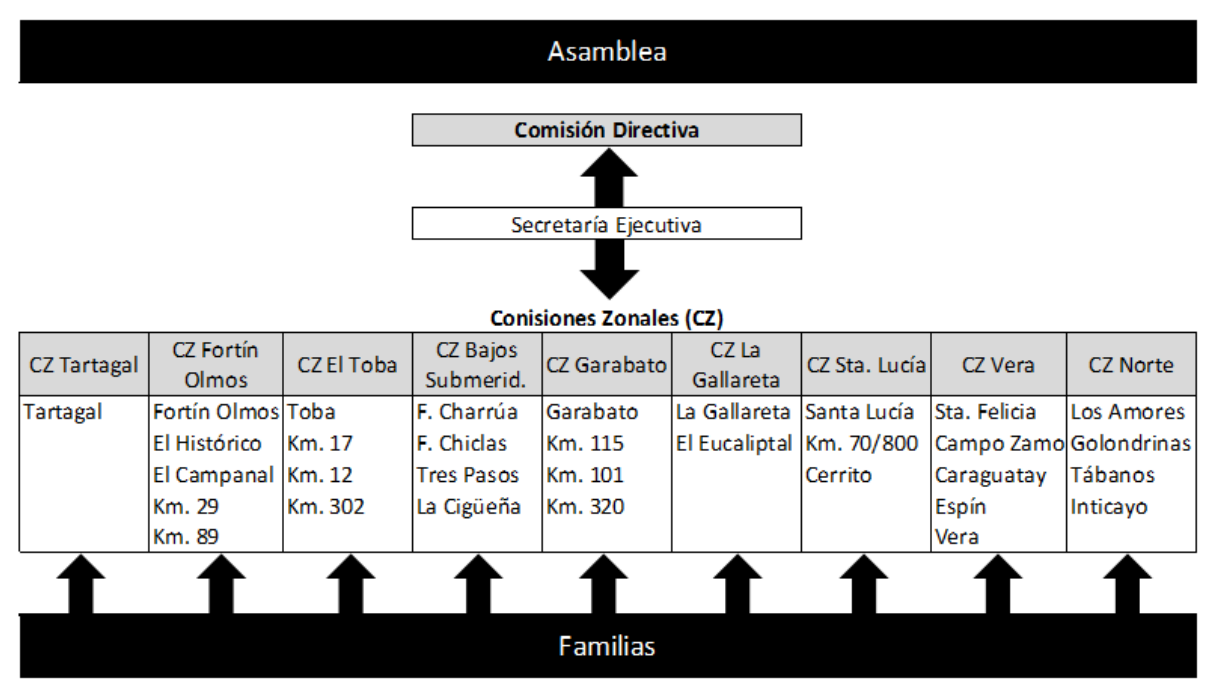

FIGURA 1

Estructura de la UOCB.

Reproducción de organigrama publicado en folleto informativo de la UOCB en 2012

A su vez, se mantuvieron los grupos de trabajo dedicados al seguimiento de las iniciativas que históricamente los han congregado en torno a temáticas productivas como la apicultura y la crianza y comercialización de ganado menor (chivos o cabritos, mayoritariamente). La UOCB ha gestionado y administra dos salas de extracción de miel (en Campo Zamo y La Gallareta), una sala de faena de ganado menor (en Fortín Olmos), una sala de usos múltiples que oficia de sede social, centro de exposición y venta de productos artesanales (en Vera), una camioneta para aspectos logísticos de la organización y otra con equipo térmico y de refrigeración para el traslado y comercialización de animales faenados. La administración de estos bienes y espacios productivo-comerciales comunes forman parte de la construcción identitaria y organizacional actual de la UOCB, en la que la participación societaria combina aspectos vinculados a un asociativismo de tipo económico con otros de tipo reivindicativo (gremial-sectorial) e identitario (territorialrural).

De este modo, siguiendo a Svampa (2008) y a Seoane et al. (2011), podemos señalar que el caso de la UOCB expresa algunas características comunes de los nuevos movimientos y experiencias asociativas de comienzos de este milenio vinculadas, por un lado, a las dinámicas de apropiación comunitaria del territorio antes mencionadas (en defensa del espacio de vida y a partir de experiencias de autogestión productiva) y, por otro lado, a una profunda revalorización y reivindicación de la noción de autonomía y de la búsqueda de formas participativas y democráticas de organización orientadas a atenuar los peligros de la burocratización y los procesos de "cooptación” política por parte de las esferas institucionales de gestión estatal.

En función de los diferentes testimonios relevados, podemos advertir el especial énfasis que ponen sus dirigentes en plantear la necesidad de constituir la UOCB como una organización autónoma respecto de las esferas gubernamentales, pero que al mismo tiempo sea un instrumento para la representación y canalización de las demandas de su base social en los ámbitos institucionales del Estado.

\subsection{Estrategias de acción}

Tal como señalamos en apartados anteriores, desde la perspectiva de la movilización de recursos la acción colectiva prospera cuando la gente tiene acceso a recursos que le permiten salir de su pasividad habitual y encuentra la oportunidad de usarlos (Tarrow, 1999). Pero, cuando lo hacen, las personas no disponen de una gama infinita de formas y medios para la acción, ya que esta se inscribe culturalmente y se comunica 
socialmente como parte de la cultura pública de una sociedad (Tilly, 1990). Los actores hacen lo que "saben hacer", es decir, lo que han aprendido en el medio social e institucional que los comprende (sindicatos, clubes de barrio, vecinales, etc.). Por ello, las estrategias de acción de la UOCB y los grupos que la conforman se vinculan estrechamente con el repertorio de acciones promovidas y aprendidas en el marco de las acciones para el desarrollo de FUNDAPAZ. De este modo, han canalizado sus demandas a través de acciones de diálogo y concertación con los poderes gubernamentales en el marco de foros y mesas de diálogo interactorales, de encuentros con legisladores y funcionarios, el contacto con organismos internacionales (para el financiamiento de proyectos) y la participación en espacios de articulación con otros actores de la sociedad civil (Iglesia, universidades).

Fruto del vínculo constitutivo que tienen con FUNDAPAZ, se observa cierto "oenegeísmo" discursivo y empírico como parte de la experiencia asociativa de la UOCB. La incidencia pública forma parte central de su repertorio de acción. Cuestión que se traduce en la orientación política general de esta organización, que se asienta en la reivindicación de lo local como espacio de desarrollo y cohesión social y en el Estado como interlocutor privilegiado para plantear sus demandas y tener injerencia en el diseño de políticas públicas.

\section{Producción discursiva y marcos interpretativos para la acción}

La producción discursiva de un actor colectivo como el que estamos analizando ha sido tematizada de modos diferentes por las dos perspectivas teóricas que venimos abordando. No obstante, ambas dan centralidad a este aspecto en la construcción identitaria de un proceso de movilización social.

Para Tarrow (2004), la coordinación de la acción colectiva depende de la confianza y cooperación que se genera entre los participantes a partir de los presupuestos e identidades compartidas que justifican, dignifican y animan su acción. El autor denomina marcos interpretativos a estos "bagajes ideológicos" y "discursos culturales" que describen los significados compartidos que impulsan a las personas a actuar en forma conjunta y operan como mediadores entre las oportunidades políticas y las estructuras movilizadoras.

Desde la perspectiva de los movimientos sociales, estos espacios discursivos se constituyen en imaginarios políticos que operan como condiciones de posibilidad para la producción política de las identidades sociales (Laclau y Mouffe, 2004, en Iglesias, 2008). Son los que permiten problematizar asuntos que antes eran considerados naturales o parte de la esfera de la vida privada y que dan origen a la identidad y acción contenciosa de un movimiento social. Estos espacios discursivos operan como un momento simbólico fundacional que supone una ruptura (politización) del devenir social e institucional dado y, al mismo tiempo, una redefinición de los actores, en términos de "amigo-enemigo", que forman parte del tejido social en conflicto.

Para el proceso de movilización social bajo análisis creemos pertinente tomar elementos de ambas perspectivas. Es relevante destacar los imaginarios políticos y tramas discursivas que han operado como condición de posibilidad para la movilización y, del mismo modo, los marcos interpretativos que dotan de un principio de inteligibilidad a las acciones para coordinar, articular o impulsar intervenciones públicas.

Para esto, hemos desagregado operativamente en tres dimensiones analíticas las producciones discursivas de la UOCB. Por un lado, haremos alusión a los significados compartidos sobre el origen de los procesos de movilización social de la UOCB, identificados en los relatos que refieran a las situaciones injustas, agraviantes o demandas sociales que han motorizado su acción. Por otro lado, haremos referencia a las propuestas de acción plasmadas en instrumentos de difusión, que forman parte de su estrategia comunicacional, cuya finalidad es resolver e interpretar las situaciones injustas y demandas específicas, dando sentido a su existencia y legitimidad a su acción social. Finalmente, daremos cuenta de las producciones discursivas que refieren a los aspectos que los identifican como parte de un proyecto común ("nosotros") y a la naturaleza del vínculo con otros actores ("ellos"): el Estado en sus diferentes niveles (institucionales y actorales), otras organizaciones sectoriales o de la sociedad civil, organismos de financiamiento, etc. (en términos de aliados y enemigos). 


\subsection{Referencias fundacionales}

Las referencias fundacionales de la UOCB hacen alusión constante a la actividad pionera de las mujeres que participaban de los grupos de desarrollo rural aglutinados por FUNDAPAZ, a los problemas con la tierra como medio de vida (lugar donde viven y producen) que los "unió en la lucha" y a la necesidad del acceso a recursos para poder producir, comercializar y organizarse.

Si bien podemos encontrar antecedentes históricos de experiencias asociativas vinculadas a la acción pastoral de la Iglesia católica de los años '60 en la localidad de Fortín Olmos (véase Büntig y Chiesa, 1972, pp. 79-84) y de las Ligas Agrarias en el norte santafesino (véase Ferrara, 1973, pp. 357-381), hay un acuerdo entre asociados y dirigentes en narrar los inicios de la UOCB y su trayectoria organizacional a partir de las intervenciones de FUNDAPAZ con aquel grupo de mujeres. Estas son mencionadas como "las pioneras" de la organización, cuestión que, como ya hemos indicado, se refleja posteriormente en su gran participación como referentes de paraje y en la composición de su Comisión Directiva.

No obstante, esta referencia fundacional femenina no se traduce en una discursividad feminista al interior de la organización. ${ }^{10}$ Más bien hace referencia a cómo los grupos de mujeres sirvieron de base para la movilización en el marco del conflicto por la tenencia de sus tierras y como lugar de aprendizaje organizacional que les permitió romper el aislamiento de los parajes rurales y canalizar sus demandas.

(...) Si tomamos la fecha de formalización de la UOCB podríamos decir que es una organización nueva, pero no es así. La historia la empezamos a hacer hace más de 25 años. Las mujeres fuimos las primeras en reunirnos con la excusa de aprender a coser, pero poco a poco el costurero empezó a dar lugar para hablar de los problemas del paraje. Así surgieron las vecinales y se empezaron a sumar los hombres. Luego empezamos a reunirnos por zona, a mirar un poco más allá del paraje con la idea de encontrar la mejor manera de estar organizados y tener peso para conseguir soluciones a los problemas que nos ocurrían a todos. Pasaron los años y nos inquietó la idea de tener una identidad propia como organización y aquí está la UOCB. Esta es nuestra principal herramienta para gestionar (...) (Fragmento del discurso de inauguración de la Sede Social de la UOCB pronunciado por la Secretaria de la Comisión Directiva, 01/06/16). ${ }^{11}$

Lo que emerge como injusto o agraviante para la movilización de este colectivo no son sólo las necesidades de encontrar respuestas a sus demandas específicas de mejoras en sus condiciones de vida (que describen como muy duras y hostiles), sino fundamentalmente la necesidad de ser "vistos" y reconocidos socialmente como actores que habitan y producen en el territorio de la cuña boscosa y los bajos submeridionales. De hecho, el conflicto que motorizó su acción se vinculó con que se estaban por vender las tierras donde vivían sus familias sin tener en cuenta su presencia histórica (de varias generaciones) como habitantes de dicho territorio. En este sentido, la UOCB emerge como herramienta de gestión, lucha y reconocimiento social: "Esto es lo que somos y lo que construimos a lo largo de todos estos años".

De este modo, el anclaje identitario que ofrece la UOCB se sostiene desde una discursividad que remite a una historia común de pertenencia territorial y de participación en procesos de lucha y gestión de recursos para la solución de sus problemas y la conquista de derechos ciudadanos.

\subsection{Propuestas de acción}

La UOCB se actualiza discursivamente a través de diversos instrumentos comunicacionales (folletos, blogs, Facebook, micro en radio local, etc.) con los que dan cuenta de sus objetivos y logros como organización, redefiniendo su identidad en función de la necesidad de ampliar su base social de representación y de presentarse frente al resto de la sociedad civil y el Estado.

El trabajo de nuestra organización está centrado en el interés de los asociados. Pero hay gestiones que benefician a otras familias que no están asociadas. En la actualidad, más de 800 familias se benefician por gestiones que realiza la UOCB. 
Nuestro trabajo se basa en la lucha por la regularización de la tierra, el desarrollo sustentable y la representación de intereses del sector de la pequeña producción (Boletín UOCB, 2012).

Las referencias a las disputas por la tierra como un medio de vida dan un matiz reivindicativo a sus discursos que, si bien buscan lograr beneficios y mejoras en las condiciones de vida y productivas de sus asociados, los trascienden e incluyen a otras familias que forman parte del universo de la pequeña producción a la que representan. La discursividad de sus propuestas y logros refleja el carácter híbrido (o transicional) de esta organización que, al igual que gran parte del universo de organizaciones de la agricultura familiar en el período estudiado (Urcola, 2018), se ha caracterizado, en su etapa fundacional, por su plurifuncionalidad, desempeñando simultáneamente sus acciones en el terreno gremial y en el económico.

La Asociación Civil UOCB, busca lograr una mejora en la calidad de vida de las familias de pequeños productores pobladores del departamento Vera. Para ello, hace gestiones ante los distintos organismos del estado nacional y provincial y entidades privadas. Formula proyectos para beneficio de sus miembros, elabora propuestas productivas y organizativas que sirvan para el desarrollo de la zona y busca su reconocimiento como sector. ${ }^{12}$

Esta ambivalencia se traduce discursivamente en la presentación de logros reivindicativos (regularización de tierras, acceso al agua, etc.) en la que se asumen como referentes del sector de la pequeña producción del departamento Vera y en otros en los que hacen referencia a los beneficios específicos para sus asociados en términos de acceso a servicios o recursos financieros (para proyectos productivos, de agregado de valor o comercialización).

Los procesos de interlocución con el Estado y con organismos internacionales de financiamiento han oficiado de contexto discursivo y marco interpretativo a través del cual la UOCB ha ido construyendo su identidad y estrategias para la canalización de sus demandas. En estos procesos de diálogo entre pobladores rurales y agencias de desarrollo rural se ha tendido (desde los 90 a esta parte) a incentivar la traducción de las demandas sociales en proyectos productivos.

El proceso de consolidación organizacional de buena parte del campo asociativo de la agricultura familiar se ha dado a través del aprendizaje que significó poder "construir la demanda social"; es decir, traducir y enunciar en forma colectiva las necesidades y situaciones injustas percibidas por los sujetos habitantes del territorio para buscar soluciones, en un proceso de diálogo y conflicto con otros actores y, en especial, con el Estado. Por estos motivos, la referencia a la "gestión de derechos" emerge en forma recurrente en sus discursos como una máxima que da sentido a sus prácticas cotidianas y legitimidad a su existencia como organización.

En este sentido, se advierte cómo el campo de las políticas públicas orientadas hacia la agricultura familiar habilitó un canal empírico y discursivo de intervención y diálogo que permitió esté pasaje de lo económicoproductivo a lo político-sectorial de muchas de las organizaciones de pequeños productores y pobladores rurales.

\subsection{Imaginarios políticos que dan sentido a su acción}

En función del proceso histórico de conformación de la UOCB reseñados hasta aquí, podemos señalar que el Estado ha oficiado de gran estructurador interno (Abrams, 2015) de sus prácticas políticas y discursivas. El Estado (en sus diferentes niveles) ha operado como fuente de legitimación y como arena política para dirimir conflictos con otros actores y canalizar sus demandas.

En las declaraciones de sus dirigentes y de sus medios de comunicación oficial (blog, Facebook, folletos, boletines, etc.), se observa la búsqueda constante de canales de diálogo con autoridades y funcionarios estatales para que reconozcan las problemáticas específicas del sector de la pequeña producción de la cuña boscosa y los bajos submeridionales y a la UOCB como interlocutora válida.

Por estos motivos, en sus discursos el Estado emerge como una entidad abstracta que oficia de fuente de reconocimiento y legitimidad (que otorga títulos de propiedad y enmarca jurídicamente su acción colectiva) 
$y$, a su vez, como una entidad concreta que se cristaliza en diferentes actores gubernamentales e institucionales con los que han establecido diferentes vínculos de diálogo y conflicto a lo largo del tiempo.

Durante el conflicto de tierras que motorizó su acción en los 90, se identificaba a los grandes productores vinculados a la Sociedad Rural y al gobierno comunal y provincial como principales adversarios. No obstante, la canalización y resolución de este conflicto se dirimió a través de las instancias institucionales legislativas estatales de la provincia, a las que los referentes de las comunidades rurales en litigio fueron a reclamar por su derecho a la propiedad de las tierras.

Del mismo modo, en el contexto de disputa institucional por el reconocimiento de su acción como organización durante la década del 2000 los funcionarios y técnicos de la SAF aparecen como principales adversarios en sus referencias discursivas. Las líneas de política pública canalizadas a través de los programas de desarrollo rural ejecutados por esta Secretaría generaron un efecto de reconocimiento y de disputa con otros actores de sus mismas características. A pesar de esto, no se buscaron alternativas por fuera del Estado, sino por dentro de él, a través del gobierno provincial, reconociendo las diferencias políticas e institucionales entre los niveles del Estado que operaban por aquel entonces en el mismo territorio.

El Estado y sus actores aparecen como lugar de diálogo para la canalización de demandas y el acceso a recursos, pero también como fuente de cooptación partidaria que amenaza su autonomía y atenta contra su identidad sectorial-territorial.

\section{Conclusiones}

En este artículo nos hemos propuesto analizar el proceso de movilización social y política que dio origen a la Unión de Familias Organizadas de Pequeños Productores de la Cuña Boscosa y los Bajos Submeridionales (UOCB). La historia de esta asociación nos ha servido como caso analítico y empírico de estudio para reflexionar sobre el universo de nuevas formas de organización y acción colectiva que, como señalamos en el planteo introductorio, surgen incipientemente en el contexto de la década de 1990 y han tendido a consolidarse a partir del nuevo milenio en torno a la figura de la agricultura familiar en los espacios de interlocución con el Estado para la generación de políticas públicas.

En función de los interrogantes planteados sobre la fuente de aglutinación de los actores que confluyen en estas organizaciones, las formas de canalización de sus demandas y el lugar que ocupa la agricultura familiar en sus discursos y programas reivindicativos, hemos establecido un diálogo analítico con las teorías de la acción colectiva. La teoría de la movilización de recursos nos brindó herramientas para la comprensión de los factores de articulación de intereses en organizaciones con cierto grado de formalización institucional para la obtención de recursos (materiales o simbólicos) y de la "estructura de oportunidades políticas" que lo hicieron posible. Mientras que la perspectiva de los nuevos movimientos sociales nos ofreció elementos para incorporar la fuerte carga identitaria que funciona como articuladora e impulsora de estos procesos organizativos.

La conjunción de intereses vinculados a la producción y comercialización de bienes agropecuarios, la mejora en la calidad de vida rural y el acceso a recursos gestionados por las comisiones y grupos temáticos de desarrollo rural promovidos por FUNDAPAZ han dado a la UOCB cierto grado de hibridismo y multifuncionalidad como rasgos constitutivos que los asemejan a otras experiencias asociativas inscriptas en el campo de la agricultura familiar en la Argentina. En estas experiencias convergen e interaccionan tanto aspectos político-contenciosos (que refieren a problemas de distribución) como culturales-identitarios (que refieren a cuestiones relativas a la defensa de formas de vida), propios de los debates entre las teorías de la movilización de recursos y de los nuevos movimientos sociales.

Las dinámicas organizacionales difundidas en el marco de las estrategias de intervención de FUNDAPAZ dieron una impronta fundacional vinculada a las acciones para el desarrollo que hacían hincapié en la organización social y productiva de los pobladores rurales para canalizar demandas y traducirlas en acciones y 
proyectos tendientes a satisfacerlas. En este sentido, la organización se ha presentado como una herramienta que les ha posibilitado romper el aislamiento de los parajes rurales (les dio identidad) y como un "instrumento de gestión” para trascender la fragmentación del reclamo individual y acceder a los recursos que les permitan mejorar sus condiciones de vida y canalizar sus demandas, fundamentalmente ante las autoridades gubernamentales.

Por otro lado, al igual que otras experiencias asociativas nacionales y provinciales surgidas durante el mismo período, el caso analizado se ha conformado en el marco de una tensión constante entre la búsqueda de autonomía y la necesidad de canalizar sus demandas al interior del Estado.

Aunque la institucionalización de los procesos de acción colectiva resulta un punto de controversia entre las dos teorías utilizadas, la formalización de las acciones de los pequeños productores de Vera se observa como un hito relevante y significativo que debe ser comprendido en el marco del proceso político y social más amplio que, en la actualidad, aglutina a un heterogéneo universo de actores agro-rurales, y no como un horizonte de clausura (de éxito o de fracaso, según el enfoque).

El proceso de discusión e institucionalidad de la temática del desarrollo rural y la agricultura familiar promovido a nivel nacional cumplió un rol vertebrador que ofició de marco para la promoción de acciones de cooperación, confrontación o ambas a la vez entre los actores vinculados a la pequeña producción campesina, indígena y/o familiar durante el período analizado.

Hemos indicado que el componente identitario que emerge como denominador común y de mayor relevancia para la articulación de estos sujetos y sus organizaciones ha sido el territorio y sus conflictos. En tanto, el Estado ha operado como "arena política" y fuente de legitimación de sus acciones. En este sentido, hay una relación constitutiva entre estas experiencias asociativas, el Estado y las políticas públicas de desarrollo rural, que no ha implicado necesariamente armonía, pero que sí ha funcionado como marco de referencia para la acción, el debate empírico-conceptual y la construcción de identidades colectivas.

\section{ReFERENCIAS}

Abrams, P. (2015). Notas sobre la dificultad de estudiar el estado. En P. Abrams, A. Gupta y T. Mitchell, Antropología del Estado (pp. 17-70). México: Fondo de Cultura Económica.

Archetti, E. (1988). Ideología y organización sindical: las ligas agrarias del norte de Santa Fe. Desarrollo Económico, 28(111), 447-461.

Büntig, A. y Chiesa, C. (1972). El catolicismo popular en la Argentina. Buenos Aires: Bonum.

Cerdá, J. M. y Salomón, A. (Comps.) (2017). Experiencias asociativas y representaciones agrarias en un agro en transformación. Buenos Aires: Ciccus.

Ferrara, F. (1973). Quéson las ligas agrarias. Historia y documentos de las organizaciones campesinas del Norte argentino. Buenos Aires: Siglo XXI.

Iglesias, E. (2008). Política y protesta. Visiones comparadas en la literatura sobre acción colectiva. En A. Fernández y C. Lesgart (Comps.). La democracia en América Latina. Partidos politicos y movimientos sociales (pp. 149-170). Rosario: Homo Sapiens.

Iglesias, E. (2015). Identidades políticas en el marco de la acción colectiva. Enfoques sobre la emergencia e institucionalización de la protesta piquetera en Argentina. Postdata 20(1), 133-157.

Lattuada, M. (2006). Acción colectiva y corporaciones agrarias. Bernal: Universidad Nacional de Quilmes.

Lattuada, M., Nogueira, M. E. y Urcola, M. (2015). Las formas asociativas de la agricultura familiar en el desarrollo rural argentino de las últimas décadas (1990-2014). CIRIEC-España, Revista de Economía Pública, Social y Cooperativa, 84, 195-228.

Martínez Espinoza, M. (2006). El Movimiento Zapatista: un análisis desde la teoría de la movilización de recursos. Kairos. Revista de Temas Sociales, 10(18). Recuperado de http://www.revistakairos.org/wp-content/uploads/Z apatismo.pdf 
McAdam, D., McCarthy, J. y Zald, M. (Comps.) (1999). Movimientos sociales: perspectivas comparadas. Oportunidades politicas, estructuras de movilización y marcos interpretativos culturales. Madrid: Istmo.

Melucci, A. (1999). Acción colectiva, vida cotidiana y democracia. México: Colegio de México.

Muzlera, J., Poggi, M. y Carreras Doallo, X. (Comps.) (2011). Aportes, sujetos y miradas del conflicto agrario argentino (1910-2010). Buenos Aires: Ciccus.

Natalucci, A. (2011). Entre la movilización y la institucionalización: los dilemas de los movimientos sociales (Argentina, 2001-2010). Polis, 10(28), 193-219.

Natalucci, A., Pérez, G., Shuster, F. y Gattoni, M. S. (2013). Territorios disputados. Movilización política y procesos de institucionalización en niveles locales de Gobierno (Argentina, 2003-2011).Revista Mexicana de Análisis Político y Administración Pública, II (2), 139-159.

Nogueira, M.E. y Urcola, M. (2013). La agricultura familiar en las políticas de desarrollo rural, ¿ hhacia una nueva agenda pública? La experiencia reciente en Argentina (1990-2011). Revista Interdisciplinaria de Estudios Agrarios, 39, 5-38.

Offe, C. (1992). La gestión politica. Madrid: Ministerio de Trabajo y Seguridad Social.

Olson, M. (1992). La lógica de la acción colectiva. México: Limusa.

Schuster, F. (2005). Las protestas sociales y el estudio de la acción colectiva. En F. Schuster et al. (Comps.). Tomar la palabra. Estudio sobre protestas sociales y acción colectiva en la Argentina contemporánea (pp. 43-83). Buenos Aires: Prometeo.

Seoane, J., Taddei, E. y Algranati, C. (2011). El concepto "movimientos sociales" a la luz de los debates y la experiencia latinoamericana reciente. Controversias y Concurrencias Latinoamericanas, Revista de la Asociación Latinoamericana de Sociología, 3(4), 169-198.

Svampa, M. (2008). La disputa por el desarrollo: territorios y lenguajes de valoración. En Autor. Cambio de época: movimientos sociales y poder politico (pp. 99-114). Buenos Aires: Siglo XXI.

Svampa, M. (2017). Movimientos sociales, tradiciones políticas y dimensiones de la acción en América Latina. En Autor. Del cambio de época al fin de ciclo. Gobiernos progresistas, extractivismo y movimientos sociales en América Latina (pp. 27-52). Buenos Aires: Edhasa.

Tarrow, S. (1999). Estado y oportunidades: la estructura política de los movimientos sociales. En D. McAdam et al. Comps.). Movimientos sociales: perspectivas comparadas. Oportunidades politicas, estructuras de movilización y marcos interpretativos culturales (pp. 31-43). Madrid: Istmo.

Tarrow, S. (2004). El poder en movimiento. Los movimientos sociales, la acción colectiva y la política. Madrid: Alianza.

Tilly, C. (1990). Modelos y realidades de la acción colectiva popular. Zona Abierta, 54, 167-195.

Touraine, A. (1985). An introduction to the study of social movements. Social Research, 52(4), 749-788.

Urcola, M. (2018). El campo asociativo de la agricultura familiar en la provincia de Santa Fe: del desarrollo rural a la movilización política (2000-2017). Población \& Sociedad, 25(2), 189-215.

Yin, R. y Helad, K. (1975). Using the case survey method to analyse policy studies. Administrative Science Quarterly, 20,371-381.

\section{Notas}

1 Reducción del número de asociados, menor participación de los productores en las actividades de su organización, creciente cuestionamiento de la representatividad de sus dirigentes, necesidad de redefinir nuevos roles institucionales y reducción o desaparición de las fuentes históricas de recursos económicos que afectan su capacidad de acción (Lattuada, 2006).

2 Entre los meses de junio de 2016 y junio de 2018 se realizaron diferentes estadías en la localidad de Vera, donde se hicieron entrevistas semiestructurados y en profundidad a informantes calificados de la organización (dirigentes, asociados, cuadros técnicos, etc.) y se recolectaron diversas fuentes documentales (actas de asambleas, artículos periodísticos, boletines informativos de la organización, contenidos escritos y audiovisuales subidos a la web por la 
organización: Blog, Facebook, YouTube, etc.), que nos permitieron recuperar la complejidad y diversidad del caso propuesto y su contexto.

3 Dichas familias viven de la producción ganadera (mayor y menor) y forestal con un fuerte componente de autoconsumo en su sistema productivo, basado en las actividades de huerta y granja. También se desarrollan otras actividades complementarias, como la apicultura y las artesanías en lana y madera. Según información brindada por la UOCB, el $60 \%$ de sus asociados vive en pequeñas localidades rurales y el $40 \%$ en el campo. Entre los asociados, hay quienes disponen de tierra propia y otros que trabajan en campos de terceros como "changarines" o se desempeñan como trabajadores temporarios en empleos rurales vinculados a la obtención de subproductos madereros como leña y carbón.

4 FUNDAPAZ es una ONG que nació en 1973 en la localidad de Vera "con el fin de promover el desarrollo sostenible en el conjunto de las comunidades indígenas y familias campesinas” del norte chaqueño argentino (véase: http://www.fund apaz.org.ar). Fue creada a partir de una donación de las religiosas de la Misión del Sagrado Corazón, quienes, preocupadas por la creciente pobreza en el norte argentino, decidieron contribuir a la creación de una organización destinada a la promoción de los más pobres en esa región del país. La acción de esta ONG fue pionera en materia de desarrollo rural en la Argentina. Tan es así que uno de sus miembros destacados, el Ingeniero Agrónomo Gastón Bordelois (presidente de su Consejo de Administración por un período), armó y coordinó posteriormente el Programa Social Agropecuario (PSA), entre los años 1993 y 2005. Del mismo modo, Jorge Pereada (fundador de esta ONG) ha impulsado a lo largo del territorio nacional las Escuelas de la Familia Agrícola (EFA) a través de la Asociación para la Promoción de Escuelas de la Familia Agrícola (APEFA), que presidió hasta el día de su fallecimiento en abril de 2017.

5 Son pequeños parajes rurales asentados desde hace más de 36 años en tierras fiscales del ferrocarril, originalmente pertenecientes a La Forestal. En la década de 1970, a través de diversas leyes de colonización, pasaron a manos del gobierno provincial, que loteó las tierras para su adjudicación. Con el paso del tiempo, los saldos de tierra de esa colonización fueron ocupados por familias de la zona en los que hoy se denominan "lote pueblo"; es decir, lotes en los que habitan entre 10 y 20 familias desde hace más de tres décadas sin título de propiedad.

6 En julio de 2007 se dictó el decreto de adjudicación. Sin embargo, frente a las demoras del proceso administrativo de entrega de los títulos, en 2008 FUNDAPAZ gestionó realizar las actuaciones legales para lograr las adjudicaciones a través de la Mesa de Tierras y la Fundación de Servicios Jurídicos Solidarios

7 A pesar de lo señalado en el testimonio, según diversas fuentes periodísticas el primer acto de entrega realizado por el Gobernador Hermes Binner fue en la localidad de Fortín Olmos en abril de 2009, mientras que el acto de entrega de escrituras y títulos de propiedad realizado en Fortín Charrúa fue en mayo de 2010.

8 La instalación discursiva que lograron las corporaciones agropecuarias y mediáticas respecto de su representación global del "campo argentino" en el marco de este conflicto generó a nivel nacional la reacción de diferentes organizaciones referentes de la pequeña producción familiar y campesina (con origen en las denominadas regiones o provincias "extrapampeanas") que intentaron distanciarse y plantear sus demandas específicas (y a veces antagónicas). Tanto a nivel provincial como nacional, estas demandas fueron incluidas en las agendas de gobierno, como puede constatarse a partir de la ya mencionada jerarquización institucional e impulso que tuvieron las políticas públicas de desarrollo rural y la agricultura familiar desde aquel entonces (véase Nogueira y Urcola, 2013).

9 Fuente: Creciendo: El Boletín de la UOCB, 3 (5), Abril-Septiembre, 2012. Véase: http://asociacionciviluocb.blogspot.c $\mathrm{om} /$ search?updated-max=2012-05-18T09:01:00-03:00\&max-results=7).

10 En este mismo sentido, Svampa se pregunta: ‘es legítimo asimilar estos procesos de feminización de las luchas con feminismo?" (2017, p. 112). Respondiendo a este interrogante, señala que el no reconocimiento del carácter "feminista" de las luchas sociales con amplia participación de mujeres no es algo nuevo, del mismo modo que no lo es el de las luchas ambientales (muy pocos activistas ambientales se reconocen inicialmente como "ecologistas" o "ambientalistas"). "La identificación es sobre todo un proceso de construcción cultural y político colectivo, que reconoce clivajes de clase y etnia, y no producto de un etiquetamiento automático que se incorpora por el mero hecho de ser mujer, en nombre de la lucha contra el patriarcado" (Svampa, 2017 , p. 113).

11 Discurso completo en: Jorge Del Barco (2016, junio, 2). Inauguración sede UOCB Margarita Silva. [Archivo de video]. Recuperado de https://www.youtube.com/watch?v=9L3cq5lfvXQ Última consulta, 20/09/17.

12 Blog de la UOCB en http://asociacionciviluocb.blogspot.com/search?updated-max=2012-05-14T22:58:00-03:00\&m ax-results=7\&start=7\&by-date $=$ false Entrada del lunes 14 de mayo de 2012. Última consulta 6/6/19.

\section{BY-NC-SA}

